financial considerations. It is evident that in foreign parts,
or in any place where there is a difficulty in disposing of the several advantages as compared with having it as a weak

\section{RECONVERSION OF NITRO-GLYCERIN INTO} GLYCERIN.

\section{By C. L. Bioxam.}

THE following experiments on this subject appear to pos sess some interest at the present moment:
1. Nitro-glycerin was shaken with methylated alcohol, which dissolves it readily. and the solution was mixed with an alcoholic solution of KIIS (prepared by dissolving KHO able rise of temperature took place, the liquid became red, arge quantity of sulphur separated, and the vitro-glyceri
was entirely decomposed.
2. Nitro-glycerin was shaken with a strong aqueous solu2. Nitro-glycerin was shaken with a strong aqueous solu-
tion of commercial $\mathrm{K}_{2} \mathrm{~S}$. The same changes were observed the liquid became opaque very suddenly when the decomposition of the nitro-glycerin was completed.

3. The ordinary yellow solution of ammonium sulphide
used in the laboratory bad the same effect as the $\mathrm{K}_{2} \mathrm{~S}$. In this case the mixture was evaporated to iryness on the steam bath, when bubbles of gas were 6 oulurel, due to the
decomposition of the ammonium nitrite. The pasty mass decomposition of the ammonium nitrite. The pasty mass
of sulphur was treated with alcobol, which extracted the plycerin, subsequently recovered by evaporation. Another sulphide was treated with excess of $\mathrm{PbCO}_{3}$ and a little lead solution. These qualitative results would be expressed by

$\mathrm{C}_{3} \mathrm{H}_{6}(\mathrm{NO})+3 \mathrm{NH}_{4} \mathrm{HS}=\mathrm{C}_{3} \mathrm{H}_{5}(\mathrm{OH})_{3}+3 \mathrm{NH}_{4} \mathrm{NO}_{2}+\mathrm{S}_{3}$

which is similar to that for the action of potassium bydro. sulphide upon gun-cotton.
4. Flowers of sulphur and slaked lime were boiled with water, till a bright orange solution was obtained. This was filtered, and some nitro-glycerin powered into it. The recases, and more agitation was required, because the nitro-
glycerin became conted with sulphur. In a few minutes, glycerin became conted with sulphur. In a few minutes, the reduclion appearing to be complete, the separated sul.
phur was filtered off. The filtrate was clear, and the sulphur bore hammering without the slightest indication of ni-
tro-glycerin. This would be the cheapest method of decomposing nitrotainable from the alkali works, might answer the purpose.

CARBONIC ACID AND BISULPHIDE OF CARBON.* By JoHN TyNDali, F.R.S.

Chemsists are ever on the alert to notice analogies and re-
emblances in the atomic structure of different bodies. They semblalices in the atomic structure of different bodies. They
long ago indicated points of resemblance between bisulphide of carbon and carbonic acid. In the case of the latter we
bave one atom of carbon united to two of oxygen, and in the bave one atom of carbon united to two of oxygen, and in the
case of the former one atom of carbon united to two of sul phur. Attempts bave been made to push the analogy still further by the discuvery of a compound of carbon and sul-
phur analogous to carbonic oxide, but bitherto, I believe,
without success. I bave now to note a resemblance of some interest to the physicist, and of a more settled character than anv bitherto observed

When, by means of an electric current, a metal is volati-
lized and subjected to spectrum analysis, the bright band of the incandescent vapor is commonily obrays emitted by the vapor by the partially cooled envelope
of its own substance which surrounds it. The effect is the same in kind as the absorption by cold carbonic acid of the beat emitted by a carbonic oxide flame. For most sources of
radiation carbonic acid is one of the most transparent of radiation carbonic acid is one of the most transparent
gases; for the radiation from the hot carbonic acid produced gases; for the radiation from the hot carbonic acid produce
in the carbonic oxide flame it is the most opaque of all.

Again, for all ordinary sources of radiant beat, bisulphide
of carbon, botb in the liquid and vaporous form, is one of the most diathermanous bodies ever known. I thought it . the most diathermanous bodies ever known. I thought it
worth while to try whether a body reputed to be analogous
to carbonic acid, and so pervious to most kinds of heat, to carbonic acid, and so pervious to most kinds of heat,
would show any change of deportment when presented to
the radiation from hot carbonic acid. Does the analogy be the radiation from hot carbonic acid. Does the analogy be
tween the two substances extend to the vibrating periods of tween the two substances extend to the vibrating periods of
their atoms? If it does, then the bisulpbide, like the carplay the part of an opaque body when presented to the radiation from the carbonic oxide flame. This proved to bisulphide transmits 90 per cent., absorbing only 10 . Fo phide transmits only 25 per cent., 75 per cent. being absorbed
For this source of rays, indeed, the bisulphile transcends, For this source of rays, indeed, the bisulphile transcends,
as an absorbent, many substances which, for all otber sources,
far transcend $i t$.

\section{THE HAIR, ITS USE AND ITS CARE. $\nmid$}

By John V. Shoemaker, A.M., M.D., Puysician to the
Philadelphia Hospital for Skin Diseases.

THE object of this paper is to briefly describe the bair and its important functions, and to suggest the proper manner of preserving it in a healthy state.
I know full well that much bas been written upon this useful part of the buman economy, but the constant increase
of bald beads and beardless faces, notwitbstanding all our of bald heads and beardless faces, notwitbstanding all our
modern advancement in the application of remedies to the modern advancement in the application of remedies to the
cure of disease, prompts me to point out to you the many ways of retaining, without medication, the bair, which is a defense, ornamentation, and adornment to the buman bodr'.
[Dr. Shoemaker bere gave an interesting history of the growth and development of the bair and its uses, which we
are compelled to omit. Then, proceeding, be said :] Now, the bair, which fulfills such an important function in ib adornment and bealth of the body, requires both constituWhen I say constitutional care, I mean that the various
organs of the body that assist in nourishing and sustaining the bair-forming apparatus should, by judicious diet, exer-

* A paper read before the Royal Society, April 5, 1883. Abstract of a paper read before the Pennoylvania State Medica
Society. at Norristown, May 10, 1888.-N. Y. Med. Jour. eise, and attention to the nervous system, be kept healthy
and sound, in order that they in turn may assist in preserv. Ing the hairs in a vigorous condition.
In the first place, that essential necessary to supply the waste and repair of all animal life, ould be selected, given, or used according to good judg, ment and experience.
Thus, mothers should feed their infants at tervals according to their age, and not permit them to constantly pull at the breast or the bottle until the little stomdisorder supervenes, often setting up a rash and interfering with the growth and development of the hair. It is like-
wise important, in case the baby must be artificially fed, to wise important, in case the baby must be artificially fed, to
select good nutritious food as near as possible like the seloct good nutritious food as near as possible like the
cogner's-cow's milk, properly prepared, being the only re-
cogstitute. Care and discretion should likewise be cognized substitute. Care and discretion should likewise be
taken by parents and nurses, after the infant bas developed taken by parents and nurses, after the infant bas developed
into childbood, to give simple, substantial, and varied food at regular periods of the day, and not in such quantities as develop them into robust and healthy men and women
and it is from neglect of these important laws of bealtb, and in allowing improper food, that very of ten bring their results in scald head, ming-worm, and scrofula, that leave
their stamp in the poor development of the bail. With the advent of youth and the advance of years, food should be
selected and partaken of according to the judgment and ex perience of its accepptable and wholesome action on the The meals should also be taken at regular intervals. At
east four hours should be left between them for the act of gestion and the proper rest of the stomach.

lifled, whe contrary, when the voice of nature bas been stifled, when judgment and experience have been set aside, fretted with overloading, and the food gulped down without being masticated, gastric and intestinal derangement superdecay and fall of the hair.

The nervous system, which is one of the most important
portions of the human structure, and which controls circuportions of the human structure, and which cont rols circulation, secretion, and nutrition, often by being impaired,
plays a prominent part in the production of baldness. Thus, plays a prominent part in the production of baldness. Thus,
t bas been demonstrated by modern investigation that the nerves of nutrition, by their defective action, are often the
cause of thinning and loss of bair. The nutritive action of a part is known to suddenly fail, the hair-forming apparatus to a white and shining appearance, and often loses at ibe
same time its sensibility ; the bairs drop out until very few remain, or the part becomes entirely bald. It is the ove taxing of the pliysical powers, excessive brain work, the
exacting demands made by parents and teachers upon child-
ren's mental faculties, the loss ren's mental faculties, the loss of sleep, incessant cares, ation of spirits, irregular and bastily bolted meals, the lac of rest and recreation, the abuse of tobacco, spirits, tea,
coffee, and drugs of all forms, that are fruitful sources of this defective action of the nerves of nut

The bair, partictilarly of the head, should also receive
marked local attention. In reference to the use of cover marked local attention. In reference to the use of cover
ings for it, I know of no better rules than those which I
laid down in my chapter on clothing in " Houseld laid down in my chapter on clothing in "Household Prac-
tice of Medicine" (vol. i.. p. 218, William Wood \& Co., New York), in which I state that the head is the only part of the
body so protected by nature as to need no artificial coverThe stiff bats so extersively worn by men produce more
less injury. Premature baldincs most frequently first less injury. Premature baldincss most frequently first attacks that part of the bead where pressure is made by the
bat. It is, indeed, a pity that custom bas so rigidly decreed that men and women must not appear out of doors with
beads uncovered. It would be far better for the bair if to be are-headed were the rule, and to wear a bat the exception.
Since we cannot change our social regulations in this reSince we cannot change our social regulations in this re-
pect, we should endeavor to render them as barmless as
possible. The forms of hats that are least injurious are : for Winter, soft bats of light weight, baving an open structure, or
pierced with numerous holes ; for Summer, light straws, so of open structure.
As regards the bead-covering of women, the fashions bave foen for several years favorable to proper form, The bonnet and bat bave become quite small, and cover but little of
the bead. This beneficial condition, bowever, is in part
counterbalanced by the weight of false curls, switches,
untfis, etc., by the aid of which women dress the lead. counterbalanced by the weight of false curls, switches,
uffs, etc., by the aid of which wnmen dress the lead. l'hese, by interfering with evaporation of the secretions, excrementitious matter, both of which are prolific sources of rapid thinning and loss of bair' in women. troducing parasites, which give rise to obstinate affections
of the scalp. of the scalp.
Cleanliness of the entire surface of the skin should next demand attention, and that should be done by using water as the medium of ablution. It is a well-known physio
logical law that it is necessary, in order to enable the skin to carry on its bealtbful action, to bave, washed off with
water the constant cast of scales which become mingled with the unctuous and saline products, together with particles of the unctuous and saline products, together with particles of
dirt which coat over the pores, and thus interfere with
the development of the hairs. Water for ablution can be of any temperature that may be acceptable and agreable, according to the custom and condition of the lyather's
bealth. Many chemical substances can he combined witl water to cleanse these effete productions from the skin. Soap is is the most efficacious of all for cleanliness, bealth,
and the avoidance of disease. Soap combines better with water to render these unctuous products miscible, and rea-
dily removes them thoroughly from the skin. The best dily removes them thoroughly from the $\$ k i n$. The best
variety of soap to use is the pure white soap, which cannot
be so easily adulterated by coloring material, or isguised hy some perfume or medicinal substance. Ablution with soap and water should be performed once or $t$ wice a week
at least, particularly to the bead and beard, in order to keep open the hail tubes so that they may take in oxygen, give in a fine, polisbed, and healthy condition. In using water water too frequently, as it of ten causes irritation of the
glands, and leads to the formation of scurf. It is equally important to avoid using on the bead the daily showerbath, which, by its sudden, rapid, and beavy fall, excites
local irritation, and, as a result, loss of bair quickly follows.
In case the bealth demands the shower-bath, the bair should be protected by a bathing cap. The most acceptable time to wash the bair, to those not accustomed to doing it with their
morning bath, is just before retiring, in order to avoid goin into the open air or getting into a draught and taking cold. After washing, the hair should be briskly rubbed with
rough towels, the Turkish towel heated being particularly rough towels, the Turkish towel heated being particularly
serviceable. Those who are delicate or sick, and fear taking
cold or being chilled from the wet or damp bairs, should cold or being chilled from the wet or damp bairs, should
rub into the scalp a little bay rum, alcobol, or oil, a short time after the parts bave been well chafed with towels. The oil is particularly serviceable at this period, as it is better absorbed, and at the same time ove
the skin which of ten follows washing.

It might be well to add in this connection that I hav frequently been consulted, by those taking salt-water baths,
as to the care of the bair during and after the bath. If the as to the care of the bair during and after the bath. If the
bather is in good bealth, and the bair is normal, the bather can go into the surf and remain at least fifteen minutes, and Ladies should permit it remain loose while doing so, after hich it can be advantageously dressed.

It is, bowever, often injurious to both men and women having some wasting of the hair to go into the surf without
properly protecting the bead; the sea water bas not, as is properly protecting the bead; the sea water bas not, as is
often ibought, a tonic action on the scalp; on the contrary, often ibought, a tonic action on the scalp; on the contrary,
it of ten excites irritation and general thinning. Again, it is in the surf one or two bours, the hair wet, and the bead unprotected from the rays of the sun. This latter class of unprotected from the rays of the sun. This latter class of soon becomes mouldy and emits a disagreeable odor, are
frequent sufferers from general loss and thinning of the An agreeable and efficient adjunct after ablution, which I bave already referred to, is oil. Oil bas not only a cleans-
ing action upon the scalp, but it also uvercomes any rough ing action upon the scalp, but it also uvercomes any rough
or uneven state of the bair, and gives it a soft and glossy The oil of ergot is particularly serviceable in fulfilling these indications, and, at the same time, by its soothing and slight astringent action upon the glands, will arrest the oils should always be preferred, as mineral oils, especially the petroleum products, bave a very poor affinity for animal Pomatum is largely used by many in place of oil, as it Pemains on the surface and gives a full appearance to the It will do no harm or no special good if it contains pure grease, wax, barmless perfume, and coloring matter, but it
is often bighly adulterated, or, the fat in it decomposing sets up irritation on the part to which it is applied. I The comb and brush fire also agents of the toilet by
The which the bair is kept clean, vigorous, and healthy. The
comb slould be of flexible gum, witb large, brout, blunt, round, and coarse teeth, having plenty of elasticity. It should be used to remove from the hairs any scurf or dirt hairs and prevent them from becoming matted and twisted The fine-tooth comb, made with the teeth much closer
Ther just named when the hair is filled with very fine particles
just

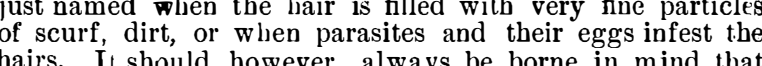
comlis. It should, bowever, always be borne in mind that
conly for the hair, and not for the scalp or the skin, which is too of ten torn and dug up by carelessly and The brush with moderately as the hair.

The brush with moderately stiff whalebone bristles may be passed gently over the bair several times during the day, smooth, soft, and clean; rough and hard brusbing the bair with brushes having very stiff bristles in them, espe-
cially the metal or wire bristles, is of no service, but often irritates the parts and causes the bair to fall out. [Dr. Shoe-
maker then denounced the use of the so-called electric brush. aying its use was injurious, as also was the effort to remove dandruff by the aid of the comb and brush. Continuing, hair be periodicully cut? It may be that cutting and shavthe permanent effect eitler upon the bair-bulb or the On the contrary, cutting and shaving will cause the hair
and o grow longer for the time being, but in the end will inevitably shorten its term of life by exbausting the nutritive
action of the bair-forming apparatus. When the bairs are action of the bair-forming apparatus. When the bairs are
frequently cut, they will usially become coar'ser, often losing ment will likewise change-brown, for instance, becoming tion, the ends of very many will be split and ragged, presenting a brush-like appearance. If the bairs appear stunted
in their growth upon portions of the scalp or beard, or gray hairs crop up bere and there, the metlod of clipping off the ends of the short bairs, of plucking out the ragged,
withered, and gray bait's, will allow them to grow stronger, Mothers, in rearing their children, should not cut their hair at certain periods of the year (during the superstitious
time of full moon), in order to increase its length and
luxuriance as they bloom into womanhood and manhood. This babit of cutting the bair of children brings evil in place of good, and is also condemned by the distir cruislsca who states that it is well known that the bair of women who possess luxuriant locks from the time of girlhood never
gain attains its original length after having once been cut. Pincus bas made the same obstrvation by frequent experiment, and be adds that there is a general opinion that requent cutting of the bair increases its length; but the
effect is different from that generally supposed. Thus, upon one oecension be states that he cut off circles of bair
$\mathrm{n}$ inch in tiamster un the beads of healthy men, and from $n$ inch in liameter un the beads of bealthy men, and from
week to week compared the intensity of growth of the
horn place with the rest of the bair. The. result was surshorn place with the rest of the bair. The. result was sur-
prising to this close and careful observer, as be found in some cases the vumbers were equal, but generally the growth

Increase in rapidity.
I might also add that I believe many beardless faces and
bald heads in middle and advancing age are often due to bonstant cutting and shaving in early life. The young girls and boys seen daily upon our streets with their closely 
faces, are, year by year, by this fashion, baving their bair-
forming apparatus overstrained.

crimping, the use of bandoline, powders, and all varieties of gum solutions, sharp hair-pins, long-pointed metal ornacurls, and frizzes, as the latter are liable to cause beadaches of castor-oil and the various mixtures extolled as the best bair-tonics, restoratives, vegetable hair-dyes, or depilatories, as they are highly injurious instead of beneficial, the major-
ity of hair-dyes being largely composed of lead salts. But, sliould your patients wish to hide their gray bairs, probably
the best bair-dye that can be used safely is pyrogallic acid the best bair-dye that can be used safely is pyrogallic acid
or walnut juice, the bairs being first washed with an alkaline solution to get rid of the grease. Nitrate of silver is also by one experienced in its use. The judicious use of these hair-dyes will give the bair above the surface of the skin a
brownish-black appearance, the intensity of the color of which depends upon the strength of the solution. But bair-
dyeing for premature grayness should be avoided, as the diseased condition may be averted by the proper remedies. taining the fashionable golden bue, as the ar'senical solution must bave their bair of a golden color, insist upon their bairdresser using the peroxide of bydrogen, which is less dangerous than the preparation first mentioned.

Perbaps one of the most pernicious compounds used for the bair at the present day is that which is sold in the shops
as a depilatory. It is usually a mixture of quicklime and arsenic, and is wrongly used and recommended at this time
by many physicians to remove bairy moles and an excessive growth of hair upon ladies' faces. Its application excites
inflammation of the skin; and, while it removes the bair from the surface for a time, it of ten leaves a scar, or makes the part rough, congested, and deformed.
In the meantime, the liair will grow after a short period stronger, coarser, and changed in color, which will even
more disfigure the person's countenance. With the present scientific knowledge of the application of electrolysis, hairs
can be removed from the face of ladies or children, or in any improper situation, in the most harmless manner with-
cut using such obnoxious and injurious compounds as depilatories. In conclusion, let me add that, if the bair becomes altered
in texture, or falls out gradually or suddenly, or changes in colur, a disease of the bair, eitber locally or generally, bas
set in, and the bair, and perbaps the constitution, now needs, as in any other disease, the constant care of the
plyysician. Thy general remedy for this or that bair disease that may de-
velop will not answer, as hair diseases, like other affections, velop will not answer, as bair diseases, like other affections,
bave no one remed which will overcome wasting, thinning
or loss of color. Pat or loss of color. Patjents reasoning upon this belief, fre-
quently apply to me for a remedy to restore their bair to its
full vigor or give them back its color. I always reply that I bave no such remedy.
The general bealth,

The general bealth, as well as the scalp and bairs, must and microscope. All changes must be watched, and the cations.
No one remedy can, therefore, under any circumstances, suit, as the remedy used to-day may be changed at the next or succeeding visit. No remedy for the bair will be neces
sary if the foregoing advice be followed which I bave jus
narrated, and which is the result of some seven years of
labor and experience. labor and experience.
The proper consideration and putting into practice of
these suggestions will nost certainiy secure to the rising these suggestions will nost certainiy secure to the rising
generation fewer bald beads and more luxuriant lair than is possessed at the present day.

\section{[Concluded from SuPPLEMENT No. 387, page 6179.]}

THE INFLUENCE OF EFFECTIVE BREATHING IN DELAYING THE PHYSICAL CHANGES INCI DENT
TO THE DECLINE OF LIFE, AND IN THE PRE VENTION OF PNEUMONIA, CONSUMPTION, AND DISEASES OF WOMEN.

By David WArk, M.D., 9 East 12th Street, New York PNEUMONIA.

DURING the past winter inflammation of the lungs bas destroyed the lives of many persons who, although they were
in most cases past the meridian of life, yet still apparently enjoyed vigorous bealth, and, I bave little doubt, would here laid down agaiust the occurrence of the disease from
which they perished been effectively practiced at the proper time.
The most important anatomical change occurring during the progress of pneumonia is the solidification of a larger or minal bronchial tubes and in the air cells of a substance by which the spongy lungs are rendered as solid and heavy as
a piece of liver. The access of the respired air to the solidi-

if a sufficiently large portion of the lungs be invaded. occurs with great rapidity; an entire lobe of the lung may
be rendered perfectly solid by the exudation from the blood of fully two pounds of solid matter in the short space of
$t$ welve bours or even less. The rapidity with which the fungs become solidified amply accounts for the promptly If recovery takes place, the foreign matter by which thelung
tissue bas been solidified is perfectly absorbed and the diseased portion is found to be quite uninjured. The only presence of foreign matter is by the oxidation-the burning -
of such impure matters; the results being carbonic acid ga that escapes by the lungs and certain materials that are eliminated chiefly by the kidneys. But when these blood im-
purities exist in the vital fluid in unusually large quantilies, purities exist in the vital fluid in unusually large quantilies,
or if the respiratory capacity be inadequate, the natural in
ternal ternal crematory operations are a partial failure. But
nature will not tolerate the presence of such impurities in nature will not tolerate the presence of such impurities in they must by unnatural means; therefore such material is
very frequently deposited in various parts of the body, the
point of deposit being often determined by some local dispoint of deposit being often determined by some local dis-
turbance or irritation.
For instance, if a person whose blood is in fairly good For instance, if a person whose blood is in fairly good
condition takes a cold that settles on his lungs, be either re
covers of it spontaneously or is readily cured by means of some cough mixture; but if bis blood be loaded with tuber-
cular matter, the latter is extremely liable to be deposited in
them for absorption. But the materials intended to enter simple cold becomes worse and persistent, in a few montbs ' living blood, in order to be fitted to become part and paicel bis lungs show signs of disorganization, and be bas con- of the organs by which power is evolved, and through the
umption of the acute or chronic type, as the case may be. use of which we see, bear, feel, think, and move. This On the other band, if the impure matter by which the wonderful process begins and is carried forward in the abolidifications of pneumonia, the latter disease is very likely he developed if a cold on the lungs be caught. sorbent system, which has been describer by Dr. Carpenter
as a great blood-making gland. But the vital transformation The liability of any individual to attacks of acute pneunce or absence in bis blood of the matter already alluded
. If bis blood be free from it, no cold, bowever severe . If his blood be free from it, no cold, bowever severe
competent to originate the disease. There can be no question but that good living and seden-
ary labits bave a strong tendency to befoul the blood; tary labits bave a strong tendency to befoul the blood;
the former renders effective respiration all the more necessary for the removal from the blood of whatever nutritive matter has been taken beyond the needs of the system, and
the latter inevitably diminishes the respiratory motions to
the lowest point consistent with physical comfort. From the lowest point consistent with physical comfort. From
these conditions originates the active predisposing cause The disease is more fatal in the very young and in the
The to aged; the mortality seems to bear a direct ratio to the re-
spiratory capacity; in young subjects the breatbing powers bave not been fully developed like the other physical capacities, while in the old the respiratory. volume has been ungs by the senile changes already detailed.
There can be no question but that protection frum cold There can be no question but that protection frum cold
nd judicious attention to the health generally, by suitable
xercise and diet, bas a powerful tendency to prevent that exercise and diet, bas a powerful tendency to prevent that overloaded condition of the blood to which I believe acute
pneumonia to be chiefly due; still I have no doubt but that the most active preventive measure that can be adopted is
keeping up the respiratory capacity to the full requirements of the system, a precaution which is specially necessary to ease-loving and high-living gentlemen who are past the
prime of ife. I am of the opinion that if such person would cultivate their breathing powers by the simple means
here recommended, their liability to pneumonia would be here recommend
notably reduced.

THE TRUE FIRST STAGE OF CONSUMPtion.

The progress of tubercular consumption bas been divided in which a deposit of tubercular matter occurs in the lung tissue, the second is entered on when the tubercles soften,
and the third when they have melted down, been expectorated, and cavities bave formed. But the real beginning of ly antedates for a long time, often for several years, the de-
posit of any tubercular matter. During all this time an expert examiner can detect the slight but very significant expert examiner can aleady taking place in the pulmonary organs.
Physicians determine the condition of the lungs chiefly through the sounds elicited by percussion of the chest walls
by the end of the middle finger, or a small rubber bammer by the end of the middle finger, or a small rubber bammer
adapted to the purpose, and by those produced by the respired air rushing into and out of the bronclial tubes and
air vesicles. The percussion sounds yielded by the chest during what bas been aptly called the pre-tubercular stage
do not differ from those elicited in bealth, because it is only when some morbid matter exists in the lungs that the percussion. note is altered, therefore negative results only are
obtained in the real first stage by this mode of examination. But important information can be obtained by interrogating
the sounds due to the inspired air rushing into and distendthe sounds due to the inspired air rushing into and distend-
ing the air vesicles. When the lungs are perfectly bealthy, ing the air vesicles. When the lungs are perfectly bealtby, omen that continue to increase as time passes, if properly
directed means be not adopted to correct the evil; but so far none of the symptoms that indicate the slightest deposil of
tubercle can be detected, but the breathing capacity of such persons is never up to the full requirements of the system.
The reader is referred to the table alreads given, which exbiThe reader is referred to the table alreads given, which exhi-
bits the decline of the breathing capacity of persons suffer-
ing from consumption in its several stages. When the ing from consumption in its several stages. When th
disease bas made such decided progress that tubercles are disease has made such decided progress that tubercles are
already deposited in the lungs in sufficient quantity to give rise to the physical signs by which their presence is proved, the vital capacity already amounts to one-third of that con-
sidered by Dr. Hutchinson to be necessary to the maintenance of health.

During the pre-tubercular stage the breathing capacily
arely falls so much as 33 per cent. below the healthy standard, but it is never up to the normal vital volume. This vidual whose relatives bave succumbed to this disease; but
it rarely attracts sufficient attention from such persons as to induce them to bave their breathing capacity measured, much less to take effective measures to bring and keep it up
to the bealthy standard. So long as there are, to them, no tangible symptoms of approaching mischief, and they feel
fairly' well, they act as if they thought "that all men were mortal but themselves." Yet it is from among persons who
have an inherited but latent tendency to tubercular disease, and whose lung power is below par, that the great army of consumptives who die every year is recruited. It is very
difficult to induce persons who ought to be interested in this matter to take effective measures for their future safety the disease often fail to shake the sufferes s confident expec-
tation of recovery; and we sometimes see them engaged in tation of recovery; and we sometimes see them engaged in I am convinced that if the suggestions laid down in this wo:k were generally reduced to practice by those who bave reason to dread the developme
valuable lives would be saved.

THE DEVELOPMENT OF TUBERCULAR MATTER L THE BLOOD.
and albuminoid elements of food are dissolved, and the fatty matters are emulsified. A uniform milky solution is thus
formed, which is rapidly absorbed into the general circula formed, which is rapidly absorbed into the general circula-
tion; some of it passes directly through the walls of the ves-
sels into the blood reaches the vital fluid by traversing the complicated series
of tubes known as the absorbent system, and the numerous of tubes known as the absorbent system, and the numerous
glands connected with it. The chief function of the starchy and fatty food elements is to keep up the physical temper-
ature, by being submitted to oxidation in the organism; vitalizing change, but are fitted to discbarge their duties in | posed to any other influences that favor its development in mitted to the action the of liver, and afterward to the influence was eaten a few bours before is thus converted into rich. scarlet arterial blood, if every part of the complex vitalizing
processes has been properly conducted. But the influence of oxygen is requisite, not only to complete the vitalization
of the embryo blood in the lungs, it is an absolutely essential element in every step of the vitalizing process in the The average quantity of food required to sustain an ordinary man in bealth and strength, I bave previously stated, is o xygen is necessary to the integrity of the vitalizing process emperature. When the requisite supply of oxygen is reduced, the extrication of heat within the system is promptly ably affected much more slowly, but with equal certainty. If the quota of oxygen existing in the arteilial blood of the
vessels whose duty it is to supply the vital fluid to the ah/sorbent system, be inadequate to enable these operations to
go on properly, the life-giving processes must necessarily be imperfectly accompl ished. Under these circumstances the ingested material is imperfectly vitalized, and is therefore
inadequately fitted to be used in building up and repairing ayed, much less stopped.

The blood possesses a definite constitution, which cannot
materially altered without the rapid development of

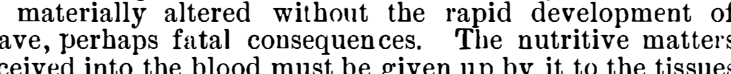
for their repair, whether such materials are well or ill fitted for the vital purposes. Dr. B. W. Carpenter, of London, work on physiology: "We frequently find an imperfectly
w w ork on physiology: "We frequently find an imperfectly matter, taking the place of the normal elements of tiscue,
both in the ordinary process of nutrition, and still more when inflammation is set up

From the examination of the blood of tuberculous subjects
it appears that, although the bulk of the coagulum obtained by stirring or beating is usually greater than that of bealthy
blood, y'et this coagulum is not composed of well elaborated fibriae, for it is soft and loose, and contains an unusually large number of colorless blood corpuscles, while the red corpuscles form an abnormally small proportion of it. We
can understand, therefore, that such a constant deficiency in
capacy for organization must unfavorably affect the ordicapacity for organization must unfavorably affect the ordi-
nary nutritive processes; and that there will be a liability to
the deposit of imperfectly vitalized matter, instead of the the deposit of imperfectly vitalized matter, instead of the
normal elements of tissue, even without any inflammation.
Such appears to be the bistory of the formation of tubercles in the lungs and other organs.
When it occurs as a lind of metamorphosis of the ordinary nutritive processes and in this manner, it may proceed tissue of the lungs ishall be replaced by tubercular deposit without any other sign than an increasing difficulty of re-
spiration." These views are strongly corroborated by the ollowing facts:

In making post mortem examinations of persons who bave
died of consumption, tubercles of different kinds are found in the same subject; some of these, baving been deposited
during what is called the first stage of the disease. before the breathing powers were much impaired, bear evident
traces of organization in the form of cells and fibers more or less obvious, these being sometimes almost as perfectly
formed as living matter, at least on the superficial part of formed as living matter, at least on the superficial part of
the deposit, which is in immediate contact with the living This variety of tubercle bas a tendency to contract and
structures and remain in the lungs without doing much injury. But as and less organization, showing a tendency to break down until at last we find crude yellow tubercles that bave become degosited.

Some cases of chronic consumption pass in a few months The progress of the disease is determined largely by the
to The progress of the disease is determined largely by the
The variety of matter which bas been partially vitalized commonly exists in small quantity, bas a strong tendency to maintain its semi-organized condition unchanged by time,
and rarely causes inflammation.
A small or moderate quantity of this sort of tubercle A small or moderate quantity of this sort of tubercle
exists in the lungs of many-persons, in whom it produces no tangible symptoms, and who are therefore quite unconscious of its presence; and even when it does exist in sufficient
quantity to develop the symptoms of lung disorder, the progress of the disease is slow, often continuing for many
years. It constitutes a variety of consumption which is specially amenable to proper treatment. On the other band,
the soft, yellow, cheesy, tubercular enatter, which is totally destitute of any vitality, is too often deposited in large
quantities, acts on the adjacen t lung tissue as an active irritant, causes inflammation, undergoes softening, forms to a premature grave. These facts, taken in connection with the immunity from lung diseases enjoyed by those
whose respiratory capacity is well developed and properly used, as well as the beneficial effects that are promptly secured in the favorable varieties of consumption by any
important increase in the vital volume, I believe fully justify the statement that tubercles are the results of defective nutri. congenital or acquired-in other words, tubercles are comficient life while undergoing the vital processes, because the
person in whom they occur babitually breathed ton lit!le resh air. the disease progressed, and the breathing capacity progres-
sively diminished, tubercular matter occurs, evincing less 